\title{
Scale model study of airflow performance in a ceiling slot-ventilated enclosure: isothermal condition
}

\author{
Hsin $\mathrm{Yu}^{\mathrm{a}}$, Chung-Min Liao ${ }^{\mathrm{b}, *}$, Huang-Min Liang ${ }^{\mathrm{b}}$ \\ ${ }^{a}$ Department of Civil Engineering, National Ilan Institute of Technology, Ilan 260, Taiwan ROC \\ ${ }^{\mathrm{b}}$ Department of Bioenvironmental Systems Engineering, National Taiwan University, Taipei 10617, Taiwan ROC
}

Received 26 November 2002; received in revised form 23 April 2003; accepted 6 May 2003

\begin{abstract}
The purpose of this study was to investigate experimentally airflow performance of wall-jet in ceiling slot-ventilated enclosure under an isothermal condition. Airspeed field measurement associated with airflow trajectory visualization was conducted in a scale model. Centerline velocity decay, airspeed profiles, jet penetration on the ceiling, jet impingement on the floor, airflow pattern, and airspeed of occupied zone were analyzed via experimental data and compared with literature theoretical expressions. Semi-empirical equations were derived to describe the wall-jet performance. The study of airflow characteristics is helpful to predict an isothermal wall-jet performance occurred in a ceiling slot-ventilated enclosure. The results provide the design guidelines of ventilation system for regulating and controlling the indoor environment.
\end{abstract}

(C) 2003 Elsevier Ltd. All rights reserved.

Keywords: Airflow performance; Airflow characteristics; Slot-ventilated; Ventilation

\section{Introduction}

Wall-jet has been extensively studied due to their importance in mechanical ventilation systems. The wall-jet that diffuses from a ceiling slot into a ventilated enclosure is defined as a plane wall jet because it is bounded by a flat surface on one side and is parallel to the surface. The plane wall jet has two-dimensional characteristics for the slot inlet aspect ratio (inlet length to inlet height) is larger than 20 [1] or conservatively 40 [2]. The plane wall jet supplied into a ventilated room is affected by opposite wall to produce reverse flow created by the wall-jet itself. The airflow pattern, wall-jet trajectory, and airspeed field of a plane wall jet are affected by the physical confinement.

The purpose of this paper is to investigate experimentally the airflow performance of plane wall jet in ceiling slot-ventilated enclosure under an isothermal condition. Airflow field and airflow trajectory visualization was measured in both ceiling and floor regions. Centerline velocity decay, airspeed profiles, jet penetration on the ceiling, jet

\footnotetext{
${ }^{*}$ Corresponding author. Tel.: +886-2-23634512; fax: +886-2 23626433.

E-mail address: cmliao@ccms.ntu.edu.tw (C.-M. Liao).
}

impingement on the floor, airflow pattern, and airspeed of occupied zone were analyzed via experimental data and compared with theoretical expressions of literature. Semi-empirical equations were established to describe the performance of wall-jet. The results of model study compared with the theory and results from previous studies may identify the reality of wall-jet performance in a confined enclosure.

\section{Theoretical background}

\subsection{Jet expansion zones}

Rajaratnam [3] pointed out that potential core, characteristic decay, and terminal regions were formed after plane wall jet exiting from an opening to a smooth plate. Potential core region is created immediately at a short length downstream of the opening where mixing of wall-jet boundary layer on wall side and shear layer of ambient room air on free boundary is not complete. The length depends on the type of opening and the turbulence of the air supply. Generally, for a slot-type diffuser, the length extends 5-10 equivalent air diffuser diameters or width. The maximum velocity 


\begin{tabular}{|c|c|c|c|}
\hline \multicolumn{4}{|c|}{ Nomenclature } \\
\hline$A$ & area $\left(\mathrm{m}^{2}\right)$ & $W$ & room width $(\mathrm{m})$ \\
\hline$A_{0}, A_{1}, A_{2}$ & constant & $x$ & horizontal distance from inlet wall $(\mathrm{m})$ \\
\hline C & peak velocity decay coefficient & $x^{\prime}$ & sum of the distance that jet traveled from ceiling \\
\hline$C_{0.5}$ & jet spread gradient & & to vertical wall and extended to the floor. \\
\hline$C_{\mathrm{d}}$ & diffuser discharge coefficient & $x_{0}$ & distance between virtual origin and inlet $(\mathrm{m})$ \\
\hline$C_{\mathrm{w}}$ & throw constant of plane wall jet & $x_{\mathrm{f}}$ & distance from inlet which the effect of opposite \\
\hline$g$ & gravitational acceleration rate $\left(\mathrm{m} \mathrm{s}^{-2}\right)$ & & wall is not detectable $(\mathrm{m})$ \\
\hline$h$ & diffuser width $(\mathrm{m})$ & $y$ & vertical distance from floor (m) \\
\hline$H$ & room height $(\mathrm{m})$ & $y_{0.5}$ & location where $U=U_{\max } / 2(\mathrm{~m})$ \\
\hline$I_{0}$ & $\begin{array}{l}\text { jet momentum function defined as } \\
\rho U_{\mathrm{d}}^{2} h / L H\left(\mathrm{~kg} \mathrm{~m}^{-2} \mathrm{~s}^{-2}\right)\end{array}$ & \multicolumn{2}{|c|}{ Greek symbols } \\
\hline$J$ & jet momentum number defined as $Q U_{\mathrm{d}} / g V$ & $\delta$ & boundary layer thickness (m) \\
\hline$K^{\prime}$ & centerline velocity constant & $\Phi$ & non-dimensional parameter defined \\
\hline$K_{\mathrm{rm}}$ & $\begin{array}{l}\text { ratio of maximum velocity at reverse flow } \\
\text { to maximum velocity at end wall }\end{array}$ & $\theta$ & $\begin{array}{l}h A_{\text {fan }} \Delta P /(\rho g)(W L)^{2} \\
\text { angle between wall-jet direction and horizontal }\end{array}$ \\
\hline$L$ & room length $(\mathrm{m})$ & $\eta$ & $y / y_{0.5}$ \\
\hline$L_{\max }$ & $\begin{array}{l}\text { maximum penetration distance from inlet } \\
(\mathrm{m})\end{array}$ & & density of air $\left(\mathrm{kg} \mathrm{m}^{-3}\right)$ \\
\hline$L_{\mathrm{jt}}$ & wall-jet throw $(\mathrm{m})$ & \multicolumn{2}{|c|}{ Subscripts } \\
\hline$L_{\mathrm{p}}$ & penetration distance from inlet $(\mathrm{m})$ & $\mathrm{d}$ & diffuser \\
\hline$L_{\mathrm{pn}}$ & impingement distance from inlet wall $(\mathrm{m})$ & $\mathrm{f}$ & floor \\
\hline$\Delta P$ & pressure difference through the inlet $(\mathrm{Pa})$ & fan & fan \\
\hline$Q$ & ventilation rate $\left(\mathrm{m}^{3} \mathrm{~s}^{-1}\right)$ & $\max$ & maximum of inertia flow \\
\hline Re & Reynolds number defined as $h U_{\mathrm{d}} / v$ & mean & mean of floor region \\
\hline $\mathrm{Rm}$ & inlet jet momentum ratio defined as & $\mathrm{rm}$ & maximum of reverse flow \\
\hline$U$ & mean air velocity $\left(\mathrm{m} \mathrm{s}^{-1}\right)$ & $\mathrm{L}$ & distance of room length \\
\hline$V$ & The volume of the ventilated space $\left(\mathrm{m}^{3}\right)$ & & \\
\hline
\end{tabular}

within this region remains unchanged and equal to diffuser velocity.

A fully developed flow of characteristic decay region is established beyond potential core region with the shear layer penetrating to the core of the wall-jet. The extent of this region depends on, among other factors, the type of opening, aspect ratio, and initial flow turbulence. Terminal region is a zone of rapid diffusion where the velocity profile degenerates and disappears within a few equivalent diameters. The potential core and characteristic decay regions dominate the performance of plane wall jet in a confined enclosure.

\subsection{Centerline velocity decay}

The centerline velocity decay for a plane wall jet in the characteristic decay region can be described as [3]

$\frac{U_{\max }}{U_{\mathrm{d}}}=C_{\mathrm{w}} \sqrt{\frac{h}{x}}$,

where $C_{\mathrm{w}}$ is referred to as the throw constant [2] and given by Adre and Albright [4]

$C_{\mathrm{w}}=\sqrt{2} C C_{\mathrm{d}}$, where $C$ is the peak velocity decay coefficient for a plane free jet and is estimated to be 2.7 [5] and $C_{\mathrm{d}}$ is the diffuser discharge coefficient that depends on the inlet configuration. Tuve [6] demonstrated that the maximum velocity of the plane wall jet was greater than that of a plane free jet by a factor $2^{1 / 2}$. The values of $C_{\mathrm{w}}$ vary from 2.20 to 3.68 depending on different studies [3,4,7-10]. ASHRAE [11] suggested another expression of the centerline velocity decay of a wall-jet with ceiling linear outlet type as

$\frac{U_{\max }}{U_{\mathrm{d}}}=\sqrt{\frac{K^{\prime} h}{x}}$,

where $K^{\prime}=5.5$.

\subsection{Velocity profile}

Rajaratnam [3] derived the dimensionless velocity profile of a plane wall jet from the empirical expression by Verhoff [12],

$\frac{U}{U_{\max }}=1.48 \eta^{1 / 7}[1-\operatorname{erf}(0.68 \eta)]$, 
where $\eta=y / y_{0.5}$ and $y_{0.5}=0.068(x+10 h)$. Schwarz and Cosart [13] expressed the profile of plane wall jet as

$$
\frac{U}{U_{\max }}=\exp \left[-0.937(\eta-0.14)^{2}\right] \text {. }
$$

Awbi [2] pointed out that Eq. (4) gives a good agreement with experimental data for $\eta \geqslant 0.14$.

\subsection{Airflow boundary layer growth}

The spread gradient of position at $y_{0.5}$ of the maximum airspeed of plane wall jet at ceiling is $\mathrm{d} y_{0.5} / \mathrm{d} x=C_{0.5}$ where $C_{0.5}$ ranges from 0.065 to $0.1[3,7,9,13,14]$. Launder and Rodi [15] derived a theoretical formula of $y_{0.5}$ as $y_{0.5}=$ 0.073 $\left(x+x_{0}\right)$. Schwarz and Cosart [13] gave the boundary layer thickness $(\delta)$ as $\delta=0.068(x+11.2 h)$. Albright [7] derived a formula of $y_{0.5}$ as $y_{0.5}=\delta / 0.14$. The spread angle of the plane wall jet ranges from $10^{\circ}$ to $12^{\circ}$, which is half value of a free wall jet [16].

\subsection{Floor velocity}

The desired near-floor airspeed in adult animal housing was $0.2-0.4 \mathrm{~m} \mathrm{~s}^{-1}$ [17]. The average airspeed in the occupied zone for human comfort has been specified as $0.15 \mathrm{~m} \mathrm{~s}^{-1}$ in winter and $0.25 \mathrm{~m} \mathrm{~s}^{-1}$ in summer [2,11].

Experiments confirmed that jet momentum number $(J)$ correlated well with floor air speed $\left(U_{\text {mean }}\right)$ and maximum air velocity in the return flow $\left(U_{\mathrm{rm}}\right)$ for various building configurations as [18-21]

$$
U_{\text {mean }}=A_{0}+A_{1} J^{A_{2}}
$$

or

$U_{\text {rm } / \text { mean }}=A_{0} J^{A_{2}}$.

Inlet jet momentum ratio $(\mathrm{Rm})$ correlates well with $U_{\mathrm{rm}}$ in an isothermal condition as $[19,21]$

$U_{\mathrm{rm}}=A_{0} \mathrm{Rm}^{0.5}$.

A dimensionless parameter, $\Phi$, which can also be used to characterize the floor velocity by the following form [18]:

$U_{\text {mean }}=A_{0} \Phi^{A_{1}}$,

where $\Phi=h A_{\text {fan }} \Delta P /(\rho g)(W L)^{2}$.

An expression of maximum floor airspeed was expressed as [19]

$U_{\mathrm{rm}}=A_{0} U_{\mathrm{d}}^{A_{1}} h^{A_{2}}$.

The ratio of $U_{\mathrm{rm}}$ to the wall jet velocity at a distance $x=L$ from the opening $\left(U_{\mathrm{L}}\right)$ was derived as [22]

$\frac{U_{\mathrm{rm}}}{U_{\mathrm{L}}}=K_{\mathrm{rm}}$, where $K_{\mathrm{rm}}$ is a weak function of room and inlet geometry and is estimated to be 0.7 [23]. Combined Eq. (1) with $x$ replacing by $x+x_{0}$, the resulting expression of centerline velocity is

$\frac{U_{\max }}{U_{\mathrm{d}}}=C_{\mathrm{w}} \sqrt{\frac{h}{x+x_{0}}}$.

The maximum floor airspeed can then be expressed as

$U_{\mathrm{rm}}=C_{\mathrm{w}} K_{\mathrm{rm}} U_{\mathrm{d}} \sqrt{\frac{h}{L+x_{0}}}$,

which is related to the centerline velocity of wall-jet at distance $L$.

\subsection{Airflow pattern and jet penetration}

Jin and Ogilvie [24] used three airflow zones: the stagnant zone (the mean velocity at floor less than $0.1 \mathrm{~m} \mathrm{~s}^{-1}$ ), the stable rotary flow (airflow pattern was fully rotary along the room perimeter and was independent with change of inlet height and inlet velocity), and the intermediate flow pattern (any flow patterns between the stagnant and stable flow pattern) to represent different types of airflow pattern under an isothermal condition.

Threshold values of parameter to maintain fully rotary airflow pattern have been identified in many studies. The threshold parameter is defined as the value of the parameter where an unchanging fully rotary airflow pattern is established. Kaul et al. [25] concluded that airflow patterns are related to the inlet jet momentum $(J)$ and the minimum inlet-jet momentum function $\left(I_{0}\right)$ that produced a stable three-dimensional eddy (rotary flow) in a condition of $I_{0} \geqslant 0.01 \mathrm{~kg} \mathrm{~m}^{-2} \mathrm{~s}^{-2}$.

Timmons et al. [26] suggested the airflow pattern was independent of Reynolds number $(R e)$ above a threshold value of about 3800 . Timmons [27] showed that the value of a threshold $R e$ was different for different enclosures and there was a proportional relationship between the required threshold Re and the physical size of the ventilated enclosure. Adre and Albright [4] and $\mathrm{Yu}$ and Hoff [28] reported that a threshold $\mathrm{Rm}$ existed between model and prototype where the airflow pattern remained unchanged for increasing airflow rates in three different enclosures.

Wall-jet penetration has been used to express airflow patterns quantitatively. Adre and Albright [4] defined wall-jet penetration as the distance from the inlet wall where the wall jet separated from the ceiling. Kaul et al. [25] defined wall-jet penetration as the distance from the inlet wall on the floor where the incoming wall-jet impinged. ASHRAE [11] defined the wall-jet throw as the distance from the supply where the centerline velocity in the wall-jet decreased to $0.25 \mathrm{~m} \mathrm{~s}^{-1}$ for most diffusers except for slot-type air diffusers, where the centerline velocity decreased to $0.5 \mathrm{~m} \mathrm{~s}^{-1}$. 
The throw of plane wall jet could be derived from Eq. (1) as

$L_{\mathrm{jt}}=\left(\frac{U_{\mathrm{d}}}{0.5}\right)^{2} C_{\mathrm{w}}^{2} h$.

Adre and Albright [4] employed a inlet jet Rm to characterize wall-jet penetration distance for the isothermal airflow in a ceiling slot-ventilated enclosure as

$\frac{L_{\mathrm{p}}}{L}=\frac{L_{\max } / L}{A_{0} \exp \left(-A_{1} \sqrt{\mathrm{Rm}}\right)+1}$.

Yu and Hoff [28] derived a similar description of penetration distance as a function of $\mathrm{Rm}$ in a ceiling slot-ventilated enclosure. Threshold inlet-jet momentum ratio reaching maximum jet penetration $\left(L_{\max } / L\right)$ was presented in both studies. Awbi and Setrak [29] suggested a theoretical expression of extreme wall-jet penetration in a ventilated room influenced by the surrounding solid boundaries as

$\frac{x_{\mathrm{f}}}{h}=0.52\left(\frac{L}{h}\right)^{1.09}$,

where $x_{\mathrm{f}}$ is the distance from inlet opening of wall-jet that the effect of the opposite wall is not detectable. The expression, $x_{\mathrm{f}}$, is similar to the maximum wall-jet penetration, $L_{\max }$, defined by Adre and Albright [4] when the airflow pattern beyond threshold of fully rotary pattern.

Karimipanah [30] stated that the jet travel length begins to be affected by the opposite wall at $0.7 \mathrm{~L}$ of the room. The influenced region remained as $0.7 \mathrm{~L}$ even the room length is varied. Nielsen [22] indicated that the maximum air velocity in the return flow (occupied zone) might occur at a distance of $2 / 3 \mathrm{~L}$ from the inlet in ceiling slot-ventilated enclosures. The position of the maximum reverse velocity is also defined as the impingement point [25].

\section{Experimental methods}

A scaled model of 1:3 representing a prototype building, measuring $L \times W \times H=1.83 \times 2.42 \times 0.9 \mathrm{~m}^{3}$, was used to study airflow performance in a confined enclosure. The slot height was $0.0127 \mathrm{~m}$ with slot width of $2.42 \mathrm{~m}$. Due to the inlet aspect ratio being much greater than 20 , resulting the airflow was treated as a two-dimensional wall jet without the effect of sidewalls [1]. The scale model was constructed by $0.0127 \mathrm{~m}$ thick plywood. The inner surfaces were sanded and painted black. The front wall was made of Plexiglas to accommodate airflow visualization. Access holes were placed on the top ceiling between inlet wall and end wall at intervals of $0.02 \mathrm{~m}$, except for the area between the inlet and a distance of $33 h$ ( $h=0.0127 \mathrm{~m}$ in the scale model $)$ from the inlet where a continuous access slot was constructed to observe clearly the wall-jet development near the inlet.

Ductwork was constructed and fitted between the circular exhaust hole and an exhaust fan (Model 3C507A; Dayton Electric MFC, Co.). Calibrated orifice plates were
Table 1

Test conditions of airflow performance under an isothermal condition

\begin{tabular}{llllll}
\hline Test & $\begin{array}{l}Q \\
\left(\mathrm{~m}^{3} \mathrm{~s}^{-1}\right)\end{array}$ & $\begin{array}{l}U_{\mathrm{d}} \\
\left(\mathrm{m} \mathrm{s}^{-1}\right)\end{array}$ & $\begin{array}{l}\Delta T \\
\left({ }^{\circ} \mathrm{C}\right)\end{array}$ & $R e$ & $\mathrm{Rm}$ \\
\hline IP1 & 0.097 & 3.14 & 0 & 2512 & 0.0460 \\
IP2 & 0.067 & 2.18 & 0 & 1745 & 0.0222 \\
IP3 $^{\mathrm{a}}$ & 0.046 & 1.50 & 0 & 1203 & 0.0105 \\
IP4 $^{2}$ & 0.033 & 1.08 & 0 & 863 & 0.0054 \\
IP5 $^{\mathrm{a}}$ & 0.024 & 0.77 & 0 & 614 & 0.0027 \\
IP6 & 0.017 & 0.54 & 0 & 435 & 0.0014 \\
IP7 & 0.009 & 0.29 & 0 & 234 & 0.0004
\end{tabular}

${ }^{\mathrm{a}}$ Measurements on ceiling region only.

used to select desired airflow rates through model. A micro-manometer (Model 1430; Dwyer Instruments, Inc.) was used to measure the pressure difference across the orifice to determine airflow rate. The orifice plates used in the pressure measurements were calibrated by a standard Venturi flow meter. The calibration curve showed a good correlation $\left(r^{2}>0.99\right)$.

Airspeed was measured using an omni-directional hot-film anemometer (Model 8470; TSI, Inc.), which was calibrated by the manufacture. The percentage of error was below 3\%. A portable data acquisition system (Model CR10; Campbell Scientific, Inc.) was used to collect data. The average over time, at a point, was used for analysis and presentation. The acquiring period for each point was fixed to $180 \mathrm{~s}$ and the sampling frequency was set at $16 \mathrm{~Hz}$ to ensure accurate time-average results for turbulent airflow [31]. Several airflow rates were chosen to encompass the anticipated stagnant and fully rotary airflow zones. The test conditions used are summarized in Table 1.

\section{Results and discussion}

\subsection{Centerline velocity decay}

The centerline velocity decreased with the extent of wall-jet travel along the ceiling. The normalized centerline velocity profiles at ceiling behave similarly when airflow rates beyond threshold value of fully rotary flow (Fig. 1A). The maximum floor velocity occurred at the impingement point of reverse flow and the jet traveled forward to the inlet-opening wall at floor surface as a plane wall jet. The impingement points at floor from inlet opening wall were about $0.6 L-0.7 L$ in different airflow rates (Fig. 1B). This value agrees with Nielsen [22] of $2 / 3 L$ from the inlet wall.

The representations of different airspeed profiles in both ceiling and floor regions could be illustrated in normalized and log-transformed coordinates along perimeter of enclosure (Fig. 2). The region of ceiling length below $10 \mathrm{~h}$ was the potential core, where the centerline velocity maintained constant and approximated to $U_{\mathrm{d}}$. The centerline velocity at position between $10 \mathrm{~h}$ and $100 \mathrm{~h}$ was characteristic decay 


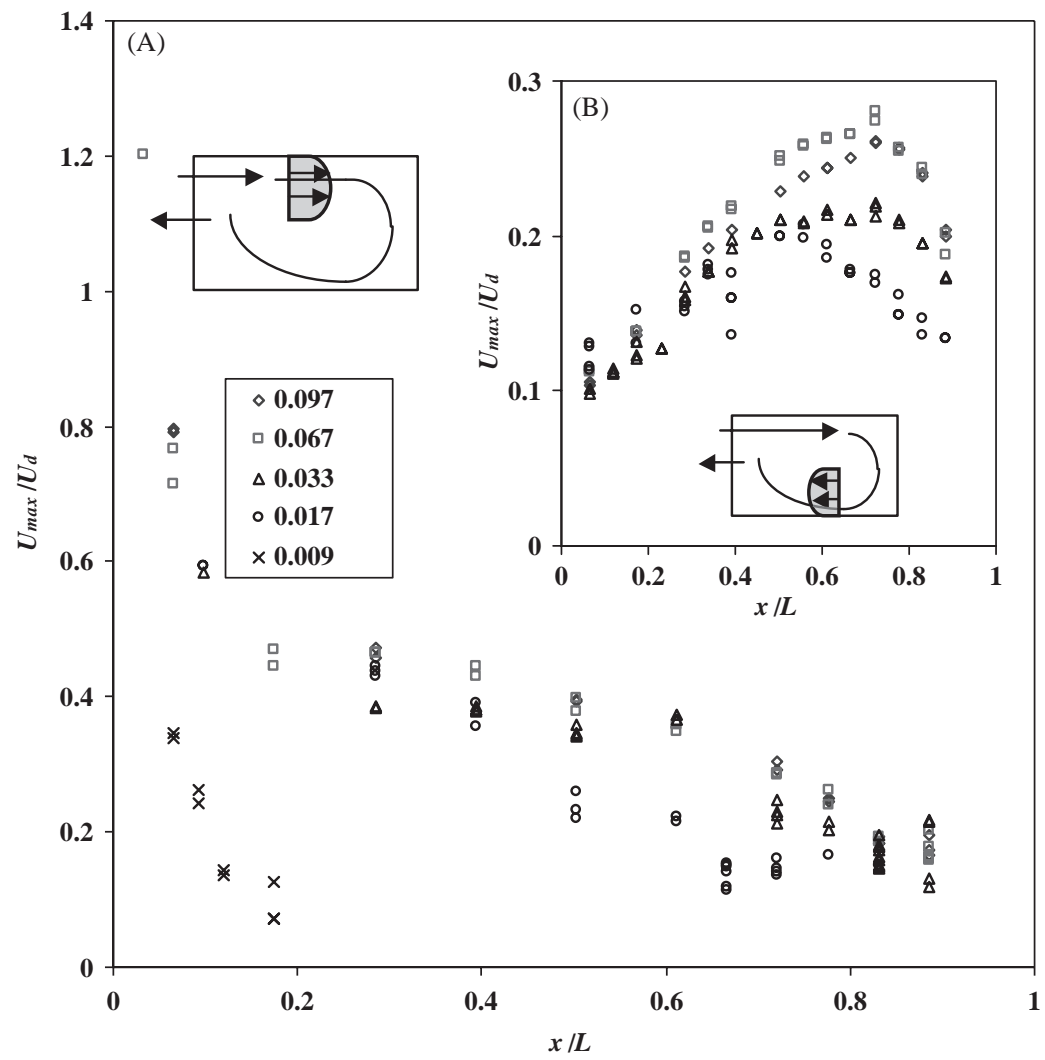

Fig. 1. Centerline velocity varied along (A) ceiling and (B) floor in different ventilation rates ranged from 0.009 to $0.097 \mathrm{~m}^{3} \mathrm{~s}^{-1}$.

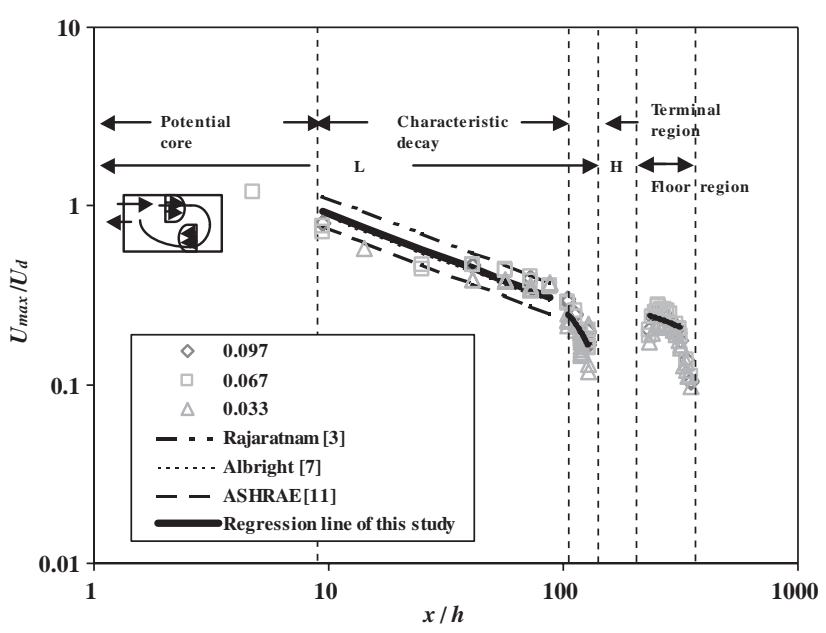

Fig. 2. Normalized centerline velocity decays along perimeter of enclosure in different ventilation rates ranged from 0.033 to $0.097 \mathrm{~m}^{3} \mathrm{~s}^{-1}$. A comparison of the fitted results with the other studies is also shown.

region in that the fitted equation of airspeed decay had the form as

$\frac{U_{\max }}{U_{\mathrm{d}}}=2.87 \sqrt{\frac{h}{x}}$.

The estimated throw constant $C_{\mathrm{w}}$ of 2.87 was within the ranges between 2.35 and 3.5 of other studies [3,7,11].
The wall-jet terminal region collapsed rapidly at distance beyond $100 h$, where the region begins to be affected by the opposite wall. The fitted equation of maximum airspeed in the terminal region had the form as

$\frac{U_{\max }}{U_{\mathrm{d}}}=2744 \frac{h^{2}}{x^{2}}$.

Fig. 2 shows that the wall-jet at the floor region behaves like plane wall jet at ceiling after the reverse flow impinged on floor. The fitted airspeed decay equation in characteristic decay region was obtained as

$\frac{U_{\mathrm{rm}}}{U_{\mathrm{d}}}=3.73 \sqrt{\frac{h}{x^{\prime}}}$,

where $x^{\prime}$ is sum of the distance that jet traveled from ceiling to vertical wall and extended to the floor. The results show that the behavior of wall-jet at floor could be identified as plane wall jet after the reverse flow impinged on floor surface (Fig. 2).

\subsection{Jet profiles and airflow boundary layer growth}

Experimental results indicate that both the isothermal jet airspeed and floor airspeed profiles have a better agreement with results obtained from Rajaratnam [3] than that 


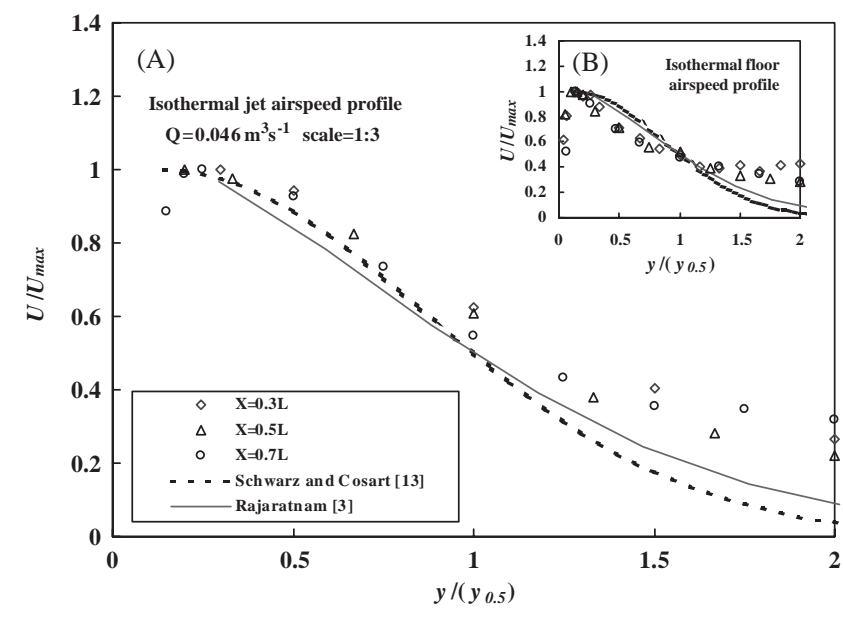

Fig. 3. Normalized airspeed profiles of plane wall jet along (A) ceiling and (B) floor with airflow rate $Q=0.046 \mathrm{~m}^{3} \mathrm{~s}^{-1}$. The profiles located in the positions of $x=0.3 \mathrm{~L}, 0.5 \mathrm{~L}$, and $0.7 \mathrm{~L}$ from the inlet wall are equals to $43 h, 72 h$, and $101 h$ in both ceiling and floor regions.

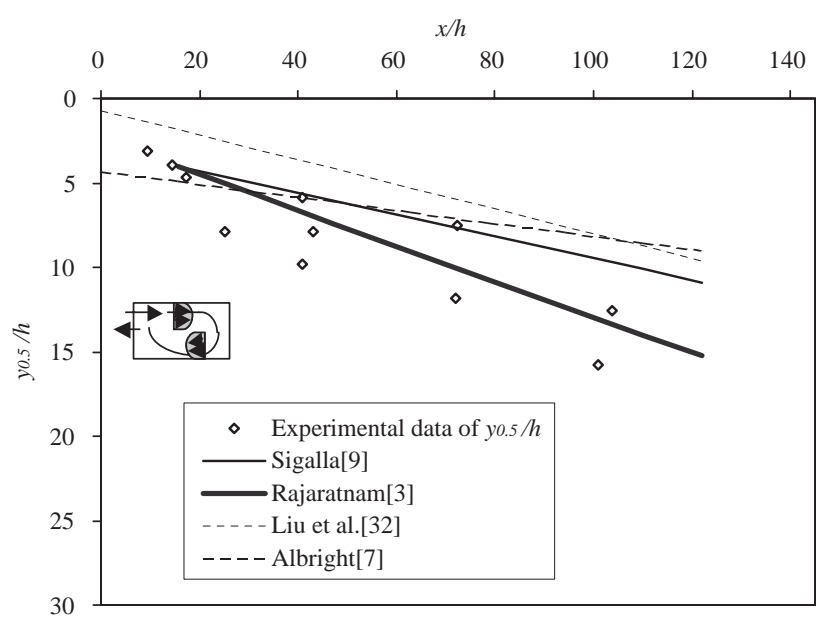

Fig. 4. Half the maximum wall-jet airspeed position measured along enclosure ceiling.

obtained from Schwarz and Cosart [13] in both ceiling and floor regions (Fig. 3). Experimental results also reveal that the maximum airspeed of wall-jet at $y_{0.5} / h$ under airflow rate of $0.046 \mathrm{~m}^{3} \mathrm{~s}^{-1}$ have a better agreement with that of Rajaratnam [3] than that of Albright [7], Sigalla [9], and Liu et al. [32] (Fig. 4).

\subsection{Floor airspeed}

Floor airspeed in an enclosure for an isothermal condition was fitted well with diffuser velocity $\left(r^{2}=0.99\right)$ (Fig. 5A). The coefficient of determination was greater than that of Nielsen [22] when $x_{0}$ is neglected (Table 2). A regression analysis for $U_{\mathrm{rm}}$ and $\mathrm{Rm}$ shows that the coefficient of determination fell between the results of Jin and Ogilvie [19] and Wang and Ogilvie [21] (Fig. 5B, Table 2). The

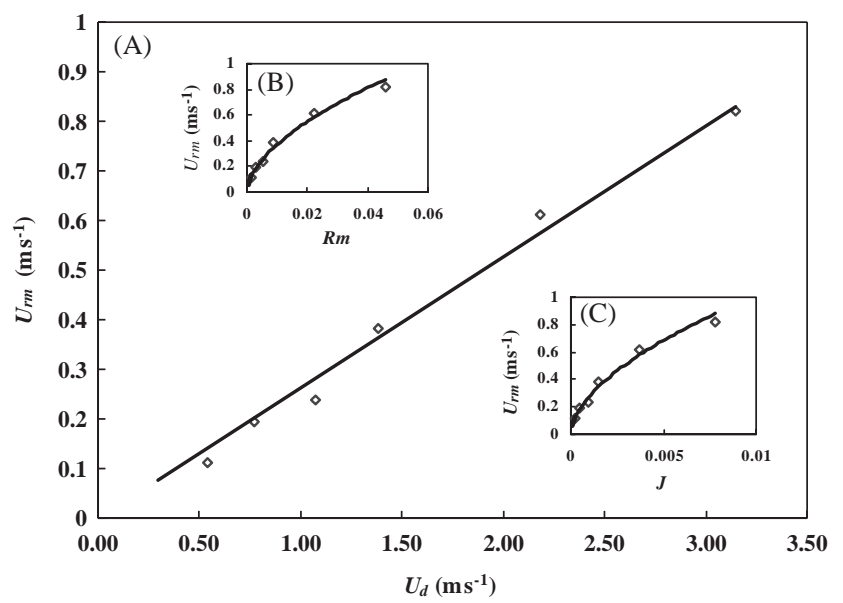

Fig. 5. Maximum floor velocity $\left(U_{\mathrm{rm}}\right)$ fitted with (A) diffuser velocity $\left(U_{\mathrm{d}}\right),(\mathrm{B})$ inlet jet momentum ratio $(\mathrm{Rm})$, and $(\mathrm{C})$ jet momentum number $(J)$.

$U_{\mathrm{rm}}$ fitted with $J$ having the same fitting results of $U_{\mathrm{rm}}$ and $U_{\text {mean }}$ fitted with $J$ by Wang and Ogilvie [21] and Jin and Ogilvie [19], respectively (Fig. 5C, Table 2). There exists a large discrepancy between $U_{\text {mean }}$ fitted with $J\left(r^{2}=0.67\right)$ by Hoff [18] and $U_{\mathrm{rm}}$ fitted with $J\left(r^{2}=0.99\right)$ in this study. The difference may result from the variance of configuration of test room.

\subsection{Airflow pattern}

Airflow pattern in the scale model was defined by the measurement and visualization of wall-jet trajectories with varied discharge rate (Fig. 6). The trajectory is the position of centerline velocity along the wall-jet.

The trajectory of jet at airflow rates ranging from 0.033 to $0.097 \mathrm{~m}^{3} \mathrm{~s}^{-1}$ was classified as fully rotary flow that traveled through perimeter of enclosure in both ceiling and floor regions (Fig. 6). Wall-jet separated from ceiling before the jet reached the extreme length, which is affected by the opposite wall, was treated as a stagnant flow under the airflow rate ranging from 0.009 to $0.024 \mathrm{~m}^{3} \mathrm{~s}^{-1}$. The trajectory of airflow rates between 0.024 and $0.033 \mathrm{~m}^{3} \mathrm{~s}^{-1}$ is experienced as an intermediate flow and results in the reverse flow ascended far from the inlet wall.

The positions of maximum airspeed attached to the ceiling when the wall-jet remained as plane wall jet until opposite wall forced the wall-jet to detach from ceiling. The distance of wall-jet separation from ceiling shown in Table 3 is based on the visualization of jet trajectories (Fig. 6). The jet throw representing penetration of wall-jet was derived from Eq. (14) with terminal velocity of $0.25 \mathrm{~m} \mathrm{~s}^{-1}$.

The ultimate wall-jet penetration distance is suggested to be $1.28-1.32 \mathrm{~m}$ when the airflow rate beyond a critical value in that the airflow pattern is fully rotary flow. The ultimate penetration distance is consistent with the wall-jet 
Table 2

Comparisons of fitted equation of floor velocity with other studies

\begin{tabular}{lll}
\hline Our study $^{\mathrm{a}}$ & Other studies & Configuration of test room $\left(L \times W \times H\right.$ m $\left.{ }^{3}\right)$ \\
\hline $\begin{array}{l}U_{\mathrm{rm}}=0.26 U_{\mathrm{d}} \\
\left(r^{2}=0.99\right)\end{array}$ & $\begin{array}{l}U_{\mathrm{rm}}=0.17 U_{\mathrm{d}} \\
\left(r^{2}=0.97\right)\end{array}$ & $0.27 \times 0.09 \times 0.09$ \\
$U_{\mathrm{rm}}=4.14 \mathrm{Rm}^{0.53}$ & $U_{\mathrm{rm}}=4.56 \mathrm{Rm}^{0.50}$ & $4.9 \times 3.8 \times(2.6-3.2)$ \\
$\left(r^{2}=0.99\right)$ & $\left(r^{2}=0.98\right)$ & $4.8 \times 4 \times 3$ \\
& $U_{\mathrm{rm}}=3.33 \mathrm{Rm}^{0.52}$ & $4.9 \times 3.8 \times(2.6-3.2)$ \\
$U_{\mathrm{rm}}=13.56 J^{0.56}$ & $U_{\mathrm{rm}}=19.33 J^{0.50}$ & {$[22,23]$} \\
$\left(r^{2}=0.99\right)$ & $\left(r^{2}=0.97\right)$ & $4.8 \times 4 \times 3$ \\
& $U_{\text {mean }}=15.02 J^{0.52}\left(r^{2}=0.96\right)$ & $10.6 \times 29.3 \times 2.3$ \\
& $U_{\text {mean }}=1652.43 J^{1.76}\left(r^{2}=0.67\right)$ & {$[21]$} \\
\hline
\end{tabular}

${ }^{\text {a }}$ Configuration of our test room is $1.83 \times 2.42 \times 0.09 \mathrm{~m}^{3}$.
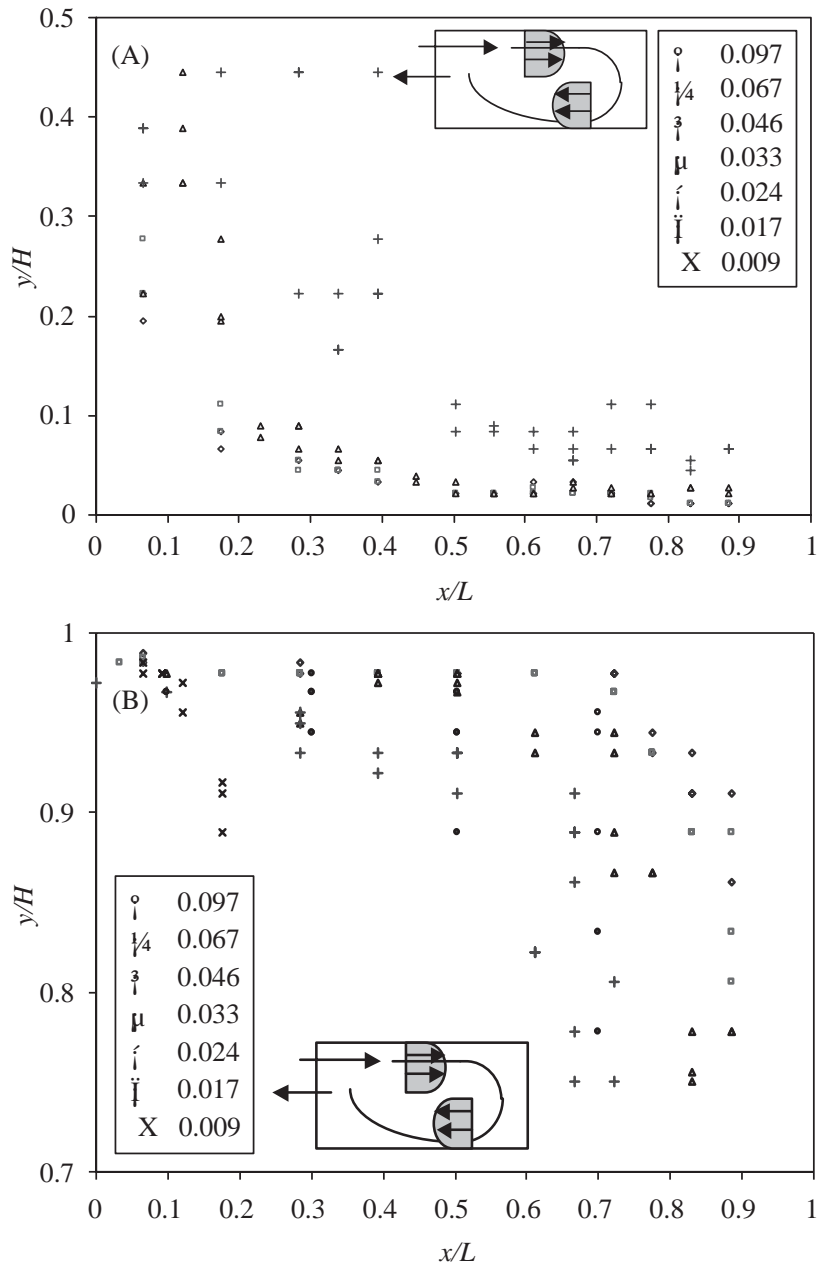

Fig. 6. Trajectory of wall-jet measured in both ceiling and floor regions in different ventilation rates ranged from 0.009 to $0.097 \mathrm{~m}^{3} \mathrm{~s}^{-1}$ for (A) $y / H=0-0.5$ and (B) $y / H=0.7-1.0$.

that reached the end of characteristic decay region at $100 h=0.7 L=1.27 \mathrm{~m}$. The normalized penetration distance at ceiling is fitted with Rm as (Fig. 7)

$$
\frac{L_{\mathrm{p}}}{L}=\frac{0.72}{196.82 \exp (-117.22 \sqrt{\mathrm{Rm})+1}} \quad\left(r^{2}>0.91\right) \text {. }
$$

Ultimate penetration distance is $0.72 \mathrm{~L}$ and is closed to the result of $0.64 \mathrm{~L}$ from Adre and Albright [4] with the similar configuration of scale model.

Awbi and Setrak [29] derived the maximum penetration of wall-jet blocked at the distance from the supply of plane wall jet as

$x_{\mathrm{f}}=0.52 h\left(\frac{L}{h}\right)^{1.09}=0.8 L=149 \mathrm{~cm}$.

The discrepancy between $x_{\mathrm{f}}$ and departure penetration distance $\left(L_{\mathrm{p}}\right)$ may result from $x_{\mathrm{f}}$ that was derived from the wall-jet boundary separated from enclosure ceiling, and $L_{\mathrm{p}}$ that was derived from the centerline velocity position departed from ceiling (Fig. 6).

In the present study, the critical value derived from the wall-jet penetration throw with terminal velocity of $0.25 \mathrm{~m} \mathrm{~s}^{-1}$ was used to define the penetration distance. Therefore, it was assumed that transition from stagnant zone to intermediate and fully rotary zones occurred at $U_{\mathrm{d}}=0.25 / C_{\mathrm{w}}(0.7 L / h)^{1 / 2}=0.87 \mathrm{~m} \mathrm{~s}^{-1}$, where the airflow rate is $0.027 \mathrm{~m}^{3} \mathrm{~s}^{-1}(R e=690)$ for the scale model. The critical discharge to distinguish intermediate flow and fully rotary flow in the model was found to be $0.034 \mathrm{~m}^{3} \mathrm{~s}^{-1}$ $(R e=880)$ that was derived from Eq. (19) in that the peak floor velocity decreases to $0.25 \mathrm{~m} \mathrm{~s}^{-1}$ as traveling through ceiling, vertical wall and floor region as

$U_{\mathrm{d}}=\frac{0.25}{3.73} \sqrt{\frac{0.7 L+H+0.7 L}{h}}=1.11 \mathrm{~m} \mathrm{~s}^{-1}$,

where the length of wall-jet traveled through ceiling, vertical wall, and floor are about $0.7 \mathrm{~L}, H$, and $0.7 \mathrm{~L}$, respectively. The length that wall-jet traveled through floor is $0.7 \mathrm{~L}$ according to the visualization and measurement of wall-jet trajectory (Fig. 6).

It is concluded that if the airflow rate were greater than threshold inlet $\operatorname{Re}$ ( 880 in this study), wall-jet traveled through perimeter of enclosure could result in a fully rotary airflow. The threshold $R e$ is less than that derived from 
Table 3

Comparisons of jet throw and departure distance of maximum airspeed position

\begin{tabular}{|c|c|c|c|c|c|c|}
\hline Airflow pattern & $\begin{array}{l}\text { Airflow rate } \\
Q\left(\mathrm{~m}^{3} \mathrm{~s}^{-1}\right)\end{array}$ & $\begin{array}{l}\text { Diffuser airspeed } \\
U_{\mathrm{d}}\left(\mathrm{m} \mathrm{s}^{-1}\right)\end{array}$ & $\begin{array}{l}\text { Distance of departure } \\
L_{\mathrm{p}}(\mathrm{m})^{\mathrm{a}}\end{array}$ & $\begin{array}{l}\text { Jet throw (Eq. (14)) } \\
L_{\mathrm{jt}}(\mathrm{m})\end{array}$ & $\begin{array}{l}\text { Normalized } \\
\text { departure } L_{\mathrm{p}} / h\end{array}$ & $\begin{array}{l}\text { Normalized jet } \\
\text { throw } L_{\mathrm{jt}} / h\end{array}$ \\
\hline Fully rotary flow & 0.097 & 3.14 & 1.32 & $16.54^{b}$ & 104 & $1302^{\mathrm{c}}$ \\
\hline Fully rotary flow & 0.067 & 2.18 & 1.32 & $7.98^{\mathrm{b}}$ & 104 & $628^{\mathrm{c}}$ \\
\hline Fully rotary flow & 0.046 & 1.50 & 1.28 & $3.79^{b}$ & 101 & $298^{\mathrm{c}}$ \\
\hline Intermediate flow & 0.033 & 1.08 & 1.28 & $1.95^{\mathrm{b}}$ & 101 & $154^{\mathrm{c}}$ \\
\hline Stagnant zone & 0.024 & 0.77 & 0.92 & 0.99 & 72 & 78 \\
\hline Stagnant zone & 0.017 & 0.54 & 0.51 & 0.48 & 40 & 38 \\
\hline Stagnant zone & 0.009 & 0.29 & 0.12 & 0.14 & 9 & 11 \\
\hline
\end{tabular}

a See Fig. 6.

${ }^{\mathrm{b}}$ Actual penetration distance is $1.28-1.32 \mathrm{~m}$ by the effect of opposite wall.

${ }^{\mathrm{c}}$ Actual penetration distance is $101 h-104 h$ by the effect of opposite wall.

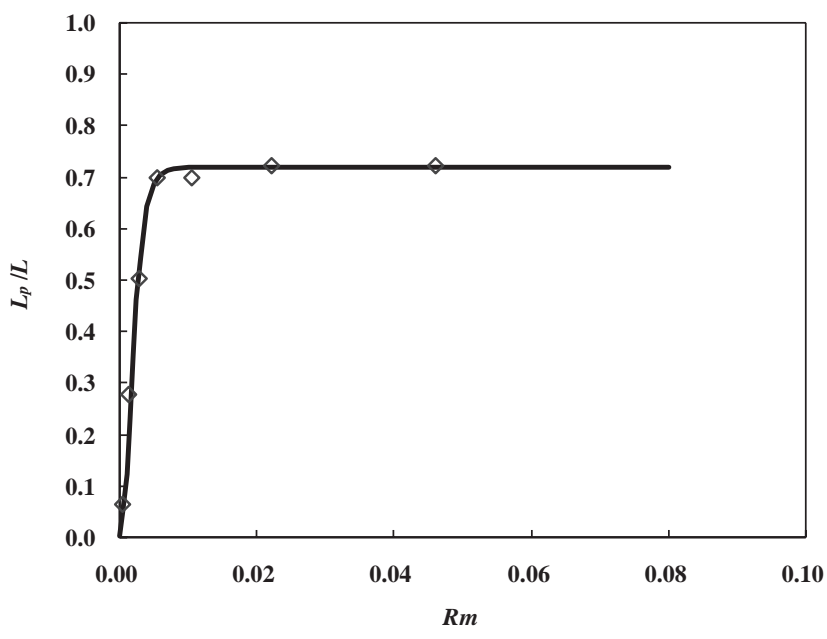

Fig. 7. Normalized wall-jet penetration distance $\left(L_{\mathrm{p}} / L\right)$ as a function of inlet jet momentum ratio $(\mathrm{Rm})$.

Timmons et al. [26], which is $R e=3800$, due to the different configuration among experimental models.

When the inlet $R e$ of airflow exceeds the threshold value of this model, airflow pattern will be fully rotary flow and is independent of increased inlet $R e$. Intermediate flow occurred when inlet $R e$ is between 690 and 880 in that the wall-jet traveled through ceiling and impinged downwardly on floor, yet the reverse flow ascended far from the inlet wall. Stagnant flow is the wall-jet with inlet $R e$ below 690 and separates from ceiling before reaching extreme jet penetration that is about $0.7 \mathrm{~L}$.

\section{Conclusions}

The results demonstrate that the centerline velocity decay in both ceiling and floor regions follow the characteristics of plane wall jet proposed by other studies. The velocity profiles of the wall-jet in both ceiling and floor regions showed a better agreement with Rajaratnam [3] than that obtained from Schwarz and Cosart [13]. The airflow boundary layer growth was consistent with that of Rajaratnam [3]. The floor airspeeds are fitted well with diffuser velocity, inlet jet momentum ratio $(\mathrm{Rm})$, and jet momentum number $(J)$, respectively. The fitted results are similar to the results obtained from Jin and Ogilvie [19], Nielsen [22], and Wang and Ogilvie [21], respectively.

Airflow trajectory was distinguished by using jet throw with terminal velocity of $0.25 \mathrm{~m} \mathrm{~s}^{-1}$. Ultimate penetration distance at ceiling is about 0.72 of room length and impingement distance at floor is $0.6-0.7$ of room length from inlet wall. Wall-jet penetration may classify the airflow pattern within an enclosure. The normalized penetration distance fitted well with inlet momentum ratio. Conclusions of the airflow patterns were similar to that of Adre and Albright [4], Awbi and Setrak [29], Jin and Ogilvie [24], Karimipanah [30] and Nielsen [22]. The consistence of wall-jet penetration appears that the estimated wall-jet trajectory and the effect of opposite wall can predict the airflow pattern of isothermal plane wall jet diffused into an enclosure.

The results suggest that airflow performance from experimental measurements can be used to predict the wall-jet behavior in ceiling slot-ventilated enclosure. The studies provide a suggestion for design guidelines of ventilation system for controlling a bioenvironmental enclosure. Future studies include the measurement of airspeed field in the surface of vertical wall, wall-jet performance under a non-isothermal condition, and the influence of real enclosure configurations of size, shape, and location of inlet and outlet, size of room, etc.

\section{References}

[1] Forthmann E. Turbulent jet expansion. Technical Memorandum No. 789, National Advisory Committee for Aeronautics, USA, 1934.

[2] Awbi HB. Ventilation of buildings. London: Chapman \& Hall, 1991.

[3] Rajaratnam N. Turbulent jets. Amsterdam: Elsevier Scientific Publishing Co., 1976.

[4] Adre N, Albright LD. Criterion for establishing similar air flow patterns (isothermal) in slotted-inlet ventilated enclosures. Transactions of the ASAE 1994;37(1):235-50.

[5] Tennekes H, Lumley JL. A first course in turbulence. Cambridge, MA: MIT Press, 1972. 
[6] Tuve GL. Air velocities in ventilating jets. ASHVE Transactions 1953;59:261.

[7] Albright LD. Environmental control for animals and plants. St. Joseph, MI: American Society of Agricultural Engineers, 1990.

[8] Li ZH, Zhang JS, Zhivov AM, Christianson LL. Characteristics of diffuser air jets and airflow in the occupied regions of mechanically ventilated rooms-a literature review. ASHRAE Transactions 1993;99(1):1119-27.

[9] Sigalla A. Measurements of skin friction in a plane turbulent wall jet. Journal of the Royal Aeronautical Society 1958;6:873-7.

[10] Walker JN. Review of the theoretical relationships of isothermal ventilation air jets. Transactions of the ASAE 1977;20:517-22.

[11] ASHRAE. ASHRAE handbook: Fundamentals. Atlanta, GA: American Society of Heating, Refrigeration and Air-Conditioning Engineers, 1993.

[12] Verhoff A. The two-dimensional turbulent wall jet with and without an external stream. Report 626, Princeton University, 1963.

[13] Schwarz WH, Cosart WP. The two-dimensional turbulent wall jet. Journal of Fluid Mechanics 1961;10(4):481-95.

[14] Myers GE. Schauer JJ, Eustis RH. Plane turbulent wall jet flow development and friction factor. ASME Journal of Basic Engineering 1963;85:47-54.

[15] Launder BE, Rodi W. The turbulent wall jet. Progressing Aerospace Science 1981;19:81-128.

[16] Etheridge D, Sandberg M. Building ventilation: theory and measurement. New York: Wiley, 1996.

[17] Albright LD. Slotted inlet baffle control based on inlet jet momentum numbers. Transactions of the ASAE 1989;32(5):1764-8.

[18] Hoff SJ. Isothermal airflow characteristics in the animal-occupied zone of a slot-ventilated swine facility. Transactions of the ASAE 1995;38(6):1843-52.

[19] Jin Y, Ogilvie JR. Airflow characteristics in the floor region of a slot ventilated room (isothermal). Transactions of the ASAE 1992;35(2):695-702.

[20] Ogilvie JR, Barber EM, Randall JM. Floor air speeds and inlet design in swine ventilation systems. Transactions of the ASAE 1990;33(1):255-9.
[21] Wang J, Ogilvie JR. Design guidelines for floor velocity distribution in slot-inlet ventilated buildings. ASAE Paper No. 94-4536, St. Joseph, MI, 1994.

[22] Nielsen PV. Numerical prediction of air distribution in rooms-status and potentials. In: Christianson LL, editor. Building systems: Room air and air contaminant distribution. Atlanta, GA: ASHRAE, 1988. p. 31-8.

[23] Nielsen PV, Restivo A, Whitelaw JH. The Velocity characteristics of ventilated rooms. Journal of Fluids Engineering 1978;100(9): 291-8.

[24] Jin Y, Ogilvie JR. Near floor air speeds from center slot air inlets in swine barns. ASAE Paper No. 90-4004, St. Joseph, MI, 1990

[25] Kaul P, Maltry W, Muller HJ, Winter V. Scientific-technical principles for the control of the environment in livestock houses and stores. Translation 430, British Society of Research in Agricultural Engineering, NIAE, Silsoe, England, 1975.

[26] Timmons MB, Albright LD, Furry RB, Torrance KE. Experimental and numerical study of air movement in slot-ventilated enclosures. Transactions of the ASAE 1980;86(1):221-39.

[27] Timmons MB. Use of physical models to predict the fluid motion in slot-ventilated livestock structures. Transactions of the ASAE 1984;27(2):502-7.

[28] $\mathrm{Yu} \mathrm{H}$, Hoff SJ. Validation of the momentum ratio concept for isothermal airflow similarity in a ceiling slot-ventilated enclosure. ASAE Paper No. 94-4582, St. Joseph, MI, 1994.

[29] Awbi HB, Setrak AA. Numerical solution of ventilation air jet. Proceedings of the Fifth International Symposium on the Use of Computers for Environmental Engineering Related to Buildings, Bath, UK, 1986.

[30] Karimipanah MT. Deflection of wall-jets in ventilated enclosures described by pressure distribution. Building and Environment 1999;34:329-33.

[31] Thorshauge J. ir-velocity fluctuations in the occupied zone of ventilated spaces. ASHRAE Transactions 1982;88(2):753-64.

[32] Liu Q, Hoff SJ, Maxwell GM, Bundy DS. A numerical study of slotted wall jets with and without ceiling. ASAE Paper No. 94-4583, St. Joseph, MI, 1994. 